\title{
Estudo Geofísico de Recursos Hídricos Subterrâneos do Município de Santarém Novo.
}

José Antônio Ferreira de Sousa, Universidade do Estado do Pará (UEPA).

Ronaldo Lopes Rodrigues Mendes, Universidade Federal do Pará (UFPA).

\section{Resumo}

O aproveitamento da água subterrânea no município de Santarém Novo é promissor. A partir da aplicação de estudos geofísicos, usando o método de eletrorresistividade, foram realizadas sondagens elétricas verticais que permitiram identificar horizontes geológicos com capacidade de dar suporte ao abastecimento público local.

\section{Introdução}

O aproveitamento de água subterrânea para o abastecimento público tem intensificado cada vez mais nos municípios paraenses. No município de Santarém Novo, isto não é diferente. Porém, para ter maior aproveitamento do potencial das formações aqüíferas e melhoria da qualidade de vida do cidadão local, o poder público necessita de maiores conhecimentos hidrogeológicos da área. Neste sentido, a UEPA, através do convênio celebrado com a SECTAM, desenvolveu em tal município estudos geofísicos preliminares que permitiram mapear os aqüíferos, de forma a apoiar o programa de abastecimento de água, além do planejamento urbano de uma forma geral. O município de Santarém Novo localiza-se na região nordeste do Pará a aproximadamente $150 \mathrm{~km}$ a NE de Belém, cujas coordenadas UTM 233907 E, $9997064 \mathrm{~N}$.

\section{Instrumentação e Operação de Campo}

Durante os trabalhos de campo foram realizadas 22 sondagens elétricas verticais (SEV) (figura 1). Os eletrodos foram dispostos segundo 0 arranjo Schlumberger (arranjo em que 0 afastamento dos eletrodos $A B$ é muito maior do que os $M N$ ), com a distância mínima entre os eletrodos de corrente igual a $2 \mathrm{~m}(\mathrm{AB} / 2=1 \mathrm{~m})$ e a máxima variável, em função da profundidade do embasamento sendo que a máxima permitida pelo equipamento é de $800 \mathrm{~m}(\mathrm{AB} / 2=400 \mathrm{~m})$. $\mathrm{O}$ aparelho utilizado nos levantamentos foi o GEOTEST, pertencente a Universidade do Estado do Pará (UEPA) e comprado com o financiamento do Fundo Estadual de Ciência e Tecnologia (FUNTEC), projetado e fabricado pela companhia Geotest Industria e Comércio de Equipamentos Eletrônicos. A potência máxima de saída e de $100 \mathrm{w}$ e corrente máxima de $500 \mathrm{~mA}$. A fonte de corrente contínua utilizada foi uma bateria de automóvel (12 V), que tem a vantagem de ser portátil e portanto podendo ser facilmente deslocada durante a operação de campo. O equipamento fornece diretamente os valores de $\Delta \mathrm{V}$ e I. Para as medidas de corrente o intervalo de leitura varia desde valores inferiores a $1 \mathrm{~mA}$ a $1 \mathrm{~A}$. O voltímetro do aparelho esta calibrado para fornecer leitura de valores desde 0,1 $\mathrm{mV}$ até valores de 199,9 mV.

A onda gerada no aparelho transmissor possui uma forma quadrada por ter sua polaridade invertida periodicamente. A reversão da polaridade permite minimizar a instabilidade nas leituras originadas pelo fenômeno de polarização de eletrodos. $\mathrm{Na}$ recepção do sinal, aparelho dispõe de filtros eletrônicos que minimizam os efeitos ruidosos gerados por correntes telúricas ou linhas de transmissão.

As demais fontes de ruídos, quando presentes, foram atenuadas durante a execução da SEV's, tomando-se cuidados operacionais.

Dessa maneira, para evitar a indução entre o circuito de emissão e recepção mantiveram-se estes 0 mais afastado possível, assim como os cabos conectados a eles.

Os levantamentos geofísicos tiveram suas medidas feitas - mais longe possível das linhas de transmissão para evitar a interferência de campo eletromagnético, induzindo correntes nos circuitos.

A resistência de contato, produzida entre o eletrodo de corrente e o terreno, foi atenuada colocando-se água salgada ao redor dos eletrodos e/ou enterrando-os o suficiente de maneira a continuarem válidas as condições de fontes pontuais.

Quando a abertura entre os eletrodos de corrente era grande o suficiente para tornar o valor de $\Delta \mathrm{V}$ (diferença de potencial) muito pequeno ou o procedimento anterior não surtia o efeito desejado, executava-se a "embreagem", aumentando-se a distância entre os eletrodos de potencial.

Freqüentemente realizava-se teste de leitura com um calibrador, fornecido pelo fabricante, assim como inspeção nos cabos e carretéis com o intuito de averiguar se estava ocorrendo fugas de corrente e que o potencial medido no aparelho era efetivamente devido aos materiais de subsuperfície.

As SEV's foram executadas nos locais onde o terreno apresentava os menores desníveis topográficos. Algumas vezes as medidas foram reduzidas por limitação topográfica.

A tabela 1 mostra os valores de $A B / 2$ e $M N$ usados no levantamento efetuado na cidade de Santarém Novo.

\section{Método Empregado na Interpretação das SEV's}

Para converter os dados geofísicos em informações geológicas, inicialmente as medidas de campo produzem um modelo geoelétrico. Em seguida faz-se correlações para a construção de um modelo geológico.

A interpretação dos dados geofísicos de campo foram qualitativa, semi-quantitativa e quantitativa. As interpretações qualitativa e semi-quantitativa forneceram uma idéia/aproximação da estruturação do subsolo 
investigado, sem preocupar-se com a determinação das espessuras nem resistividades em valor absoluto, apenas com as relações de igualdade/desigualdade entre certas características evidenciadas pelas medidas geofísicas, o que proporcionou informações acerca da localização e forma das camadas e profundidade máxima ou mínima do embasamento e outras.

$\mathrm{Na}$ interpretação quantitativa foram estimados os valores numéricos dos parâmetros de modelos de maneira que as geometrias destes, foram as mais próximas possível da geometria da fonte dos dados coletados. Neste tipo de interpretação podem ser usados os métodos comparativos, direto e inverso. Em nosso caso foi empregado apenas o método direto.

\section{Método direto}

O tratamento quantitativo dos parâmetros geoelétricos pelo método direto consiste em calcular a resposta para um modelo teórico, escolhido para representar a subsuperfície investigada, interagindo através do fornecimento dos valores de resistividade e espessura do modelo e comparando visualmente na tela do monitor do computador, até se obter um ajuste satisfatório com a curva de campo. O cálculo dos valores de resistividade aparente para a confecção da curva teórica, introduzindose os valores de resistividade e espessura para o modelo escolhido para representar o subsolo sob estudo foi realizado pelo programa computacional EGS/SEV1D desenvolvido no Departamento de Geofísica da Universidade Federal do Pará.

Especificamente, os procedimentos para a interpretação quantitativa direta dos dados das SEV's foram:

1. Os valores de resistividade aparente medidos nas SEV's foram plotados em papel bi-logarítmicos, durante a coleta de dados e, posteriormente suavizados para eliminar as pequenas perturbações no formato da curva introduzidas por ruídos e corrigir as descontinuidades nas curvas provenientes da mudança de posição dos eletrodos de potencial quando das realizações das "embreagens";

2. A interpretação das curvas de sondagens foi realizada assumindo-se um modelo geoelétrico de camadas homogêneas e isotrópicas separadas por superfícies planas e horizontais. A escolha do modelo unidimensional para a subsuperfície da cidade de Santarém Novo teve por base informações geológicas superficiais e a análise detalhada de todas as curvas de sondagens obtidas possibilitando a definição do número de camadas de cada curva;

3. Com o intuito de determinar os valores numéricos dos parâmetros resistividade e espessura de cada horizonte dos modelos adotados, fez-se sucessivos ajustes, atribuindo-se valores de resistividade e espessura para as " $n$ " camadas estimadas para o modelo, até se conseguir uma boa aproximação entre a curva gerada para o modelo e a de campo. Os valores numéricos dos parâmetros do modelo, cujo ajuste foi o mais preciso possível, foram adotados como os possíveis valores dos parâmetros geoelétricos da subsuperfície investigada.

\section{Geologia}

A região nordeste do Pará é composta basicamente pelas formações Barreiras e Pirabas, recobrindo o Grupo Gurupi e o embasamento cristalino.

Embasamento e Grupo Gurupi

O embasamento cristalino é constituído por rochas PréCambrianas que formam o Cráton do São Luís e a faixa de dobramentos do Gurupi. Os litotipos mais comuns são granitos e gnaisses pertencentes ao complexo Maraçumé.

O Grupo Gurupi é disposto discordantemente sobre o embasamento. Também com idade Pré-Cambriana, é composto por metassedimentos de baixo grau metamórfico, principalmente quartzitos e filitos.

\section{Formação Pirabas}

Com idade Terciária (Mioceno Inferior) foi formada pela transgressão e regressão marinha do antigo mar de Pirabas, sendo, por isso, constituída por sedimentos de origem marinha e com influencias lagunares. Apresenta um elevado conteúdo fossilífero em meio a calcários. Os litotipos mais freqüentes são argilas laminadas não carbonáticas, calcarenitos estratificados, calcários maciços e biocalcirutitos.

No município de Salinópolis, a cerca de $35 \mathrm{Km}$ de Santarém Novo, esta formação ocorre a partir de $28 \mathrm{~m}$ de profundidade e com espessura média de 100 m (CPRM 1978). Tancredi et al (1982) descrevem neste município, poços com calcários e argilas e arenitos pertencentes a esta formação. Segundo estes autores, a explotação de água na Formação Pirabas somente são favoráveis em seus horizontes areníticos, com profundidades em torno de $100 \mathrm{~m}$.

Em São João de Pirabas, a cerca de $25 \mathrm{Km}$ de Santarém Novo, a formação Pirabas encontra-se a partir de 25 a 30 $\mathrm{m}$ de profundidade e se estende até cerca de $120 \mathrm{~m}$ (Lopes 1996).

\section{Formação Barreiras}

Esta formação aflora em grande parte da região. Depositado em ambiente continental, tem idade Terciária e possui litologias bastante variadas. Possui argilas multicoloridas, sedimentos inconsolidados argiloarenosos e areno-argilosos, arenitos e siltitos.

Bastante marcante também são os arenitos ferruginosos (Grês do Pará), descontínuos, por vezes formando blocos soltos e irregulares e de tamanhos bastante variados.

Em Salinópolis esta formação apresenta boas possibilidades de explotação de água, com profundidade máxima igual a 40 m (Tancredi et al 1982). Em São João de Pirabas esta formação se apresenta com profundidade variável entre 25 a 30 m (Lopes 1996).

\section{Resultados}

Nos levantamentos dos dados de campo tomou-se o cuidado em minimizar os efeitos dos fenômenos não considerados no modelo físico-matemático utilizado na fase interpretativa, tais como: elevada resistência de contacto entre o eletrodo e o terreno e a indução 
eletromagnética entre os circuitos de emissão e recepção.

As informações geológicas disponíveis da área sob investigação, apresentadas no item Geologia, resultaram do estudo realizados por outros pesquisadores em municípios próximo da área investigada. Não se conseguiu informações sobre a existência de furos estratigráficos ou quaisquer dados acerca das características hidrogeológicas da subsuperfície da área pesquisada, assim como trabalhos geofísicos anteriores. A escassez de tais informações não permitiu uma correlação mais completa entre os horizontes geoelétricos conseguidos na interpretação.

A tabela 2 ilustra os resultados obtidos da interpretação quantitativa de cada uma das 22 SEV's efetuadas no município de Santarém

Conforme observado a tabela 2 , as curvas de resistividade aparente foram interpretadas como modelo geoelétrico de 6 e 7 camadas, refletindo 0 comportamento lito-estratigráfico da geologia da área sob investigação. As curvas apresentam padrões distintos, porém, a maioria apresenta o ramo final ascendente próximo de $45^{\circ}$, espelhando os efeitos do embasamento cristalino não fraturado.

Como todas as SEV's foram realizadas sobre as vias pública da cidade de Santarém Novo, em locais sem pavimentação asfáltica, ou em estradas vicinais do município, o primeiro horizonte elétrico, cuja resistividade varia entre 150 a $2.000 \Omega . m$ e espessura de 0,2 a $0,8 \mathrm{~m}$, refere-se ao solo/aterro presente naqueles locais. Os menores valores de resistividade, no intervalo de 160 a $883 \Omega$.m estão relacionados aos capeamentos de piçarra que foram executados em algumas vias ou estradas vicinais. Isto porque normalmente este tipo de aterro é colocado sob intensa compactação no intuito de reduzir o volume de vazios e, consequentemente, a condução iônica, principal forma de propagação da corrente elétrica nos materiais geológicos, fica comprometida. Os maiores valores de resistividade aparente, variando de 1.000 a $2.000 \Omega$.m, foram medidos nos locais onde o material geológico do segundo horizonte aflorava e já se apresentava intensamente intemperizado.

A variação nos valores de resistividade aparente verificados neste horizonte indicam uma forte heterogeneidade lateral. Este efeito superficial pode deslocar a curva de sondagem em um ou outro sentido, ocasionando ambigüidade na interpretação do dados eletroresistivos. Para evitar este efeito, tomou-se o cuidado de posicionar os eletrodos de potencial sobre o solo de textura o mais homogêneo possível.

O segundo horizonte geoelétrico identificado na interpretação das SEV's apresenta resistividade entre 640 a $8.860 \Omega . m$ e espessura que varia de 1 a $16 \mathrm{~m}$. Face a composição geológica da área sob investigação presume-se que este horizonte esteja preenchido por um material arenoso-argiloso.

O terceiro horizonte detectado na interpretação, cuja resistividade varia de 2900 a 76 $\Omega . m$ e espessura variando no intervalo fechado de 3 a $32 \mathrm{~m}$ pode ser definido como um substrato de transição entre os segundo e quarto horizontes. Como ilustração desta hipótese tem-se as SEV'S 2, 3, 5 e 16, cujos valores de resistividade sugerem que este horizonte seja uma continuação da camada sobrejacente. Por outro lado as SEV's 4, 7 e 9, em que as resistividades obtidas são baixas, podem ser associadas a uma porção da camada subjacente.

O quarto horizonte geoelétrico, que apresenta resistividade com valor mínimo de $31 \Omega$.m e máximo de $1500 \Omega . m$ e espessuras de 5 a $40 \mathrm{~m}$, foi interpretado como preenchido por material argilo-arenoso, sendo que em algumas SEV's, tal como na 2, apresenta um prolongamento do segundo horizonte, e em outras lentes do quinto horizonte, conforme indicam as SEV's 7 e 14.

A geologia da área indica que o quinto horizonte, tendo a resistividade variando de $3 \Omega . m$ a $200 \Omega . m$ e espessura de $15 \mathrm{~m}$ a $65 \mathrm{~m}$, é uma área de transição entre o quarto e o sexto horizonte.

Correlacionados os valores de resistividade, que na maioria das SEV's varia de 2 a $30 \Omega . m$ e espessura variando entre 15 a $90 \mathrm{~m}$, com a geologia da área sob investigação pode-se inferir que este horizonte geoelétrico é constituído por calcário.

O último horizonte geoelétrico obtido da interpretação quantitativa das SEV's equivale ao substrato cristalino, composto por gnaisses de composição granítica.

\section{Conclusões}

A interpretação dos dados eletrorresistivos coletado no município de Santarém Novo, possibilitou a definição da geologia da subsuperfície e, por conseguinte, as potencialidades hídricas dos estratos. Da análise das SEV's conseguiu-se definir 7 horizontes geoelétricos, quais sejam:

- O primeiro, cujas resistividades variam entre 150 a $2.000 \Omega$.m foi atribuído ao solo aterro, comum como revestimento de estradas de terra batida. Os maiores valores de resistividade, foram atribuído ao afloramento do material que compõe o segundo horizonte;

- O segundo horizonte, que apresenta espessura variando de 1 a $16 \mathrm{~m}$ e resistividade entre 640 a 8.860 $\Omega . m$ foi identificado como sendo arenoargiloso;

- O terceiro estrato, cujas espessuras variam entre 3 a $32 \mathrm{~m}$ e com valores de resistividade entre 2900 a 76 $\Omega . m$, foi definido como uma faixa de transição entre o segundo e quarto horizontes. Neste, não se deve descartar a possibilidade de haver água em função dos baixos valores de resistividade encontrados na interpretação;

- O quarto horizonte geoelétrico, com espessuras variando de 5 a $40 \mathrm{~m}$ e resistividades de 31 a 1500 $\Omega . \mathrm{m}$, face a estes últimos valores sugere ser um estrato formado por material argilo-arenoso. Este horizonte também possui potencial de armazenamento de água, a medida que também

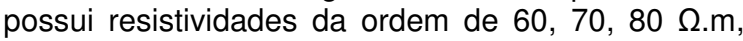
típica de areias com água doce;

- O quinto horizonte se mostra uma faixa de transição entre o quarto e o sexto horizontes, uma vez que a

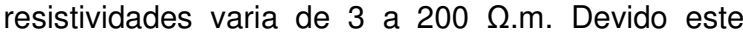
intervalo de resistividades e considerando as SEV`s 
$16,17,19,20$ e 21 infere-se que este estrato possa ser formado por areias impregnada de água;

- O sexto horizonte, em função dos valores de resistividade encontrados (2 a 48 $\Omega . m$ ), foi interpretado como constituído por calcários, calcarenitos e margas, os quais apresentam possibilidade de acumular água em seu interior. Nas SEV's 3, 8, 10 e 14 este horizonte não foi encontrado;

\section{Agradecimentos}

Ao Fundo Estadual de Ciência e Tecnologia do Estado do Pará (FUNTEC), pelo financiamento, sem o qual este trabalho não teria sido desenvolvido.

À Universidade do Estado do Pará, em especial à PróReitoria de Pesquisa e Pós-Graduação (PROPESP), pelo apoio na implementação do convênio e demais contribuições institucionais.

\section{Referências}

CPRM. Companhia de Pesquisa de recursos Minerais. 1978. Projeto COSANPA. Relatório final do poço 4SL-01PA. Belém. $9 \mathrm{p}$.

Tancredi, A. C. F. N. S.; Serra, V. H.; Santos, J. C. A. 1982. Estudos hidrogeológicos de Salinópolis-Pará. IDESP. Belém. $10 \mathrm{p}$.

Lopes, E. S. 1996. Investigação por eletrorresistividade de ambientes cársticos no município de São João de Pirabas - PA. Dissertação de mestrado. CG. UFPA. 88 p. 


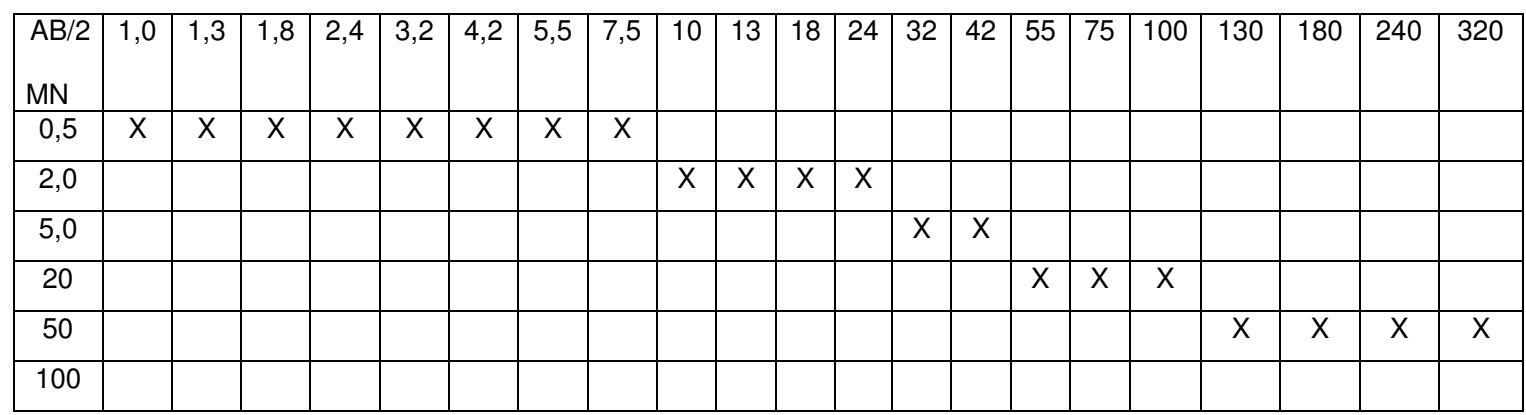

Tabela 1 - Valores de AB/2 e MN usados na investigação.

\begin{tabular}{|c|r|r|r|r|r|r|r|r|r|r|r|r|r|}
\hline & \multicolumn{1}{|c|}{ ESPESSURA DAS CAMADAS $(\mathrm{m})$} & \multicolumn{6}{|c|}{ RESISTIVIDADE DAS CAMADAS $(\Omega, \mathrm{m})$} \\
\hline $\mathrm{SEV}$ & $\mathrm{h} 1$ & $\mathrm{~h} 2$ & $\mathrm{~h} 3$ & $\mathrm{~h} 4$ & $\mathrm{~h} 5$ & $\mathrm{~h} 6$ & $\rho 1$ & $\rho 2$ & $\rho 3$ & $\rho 4$ & $\rho 5$ & $\rho 6$ & $\rho 7$ \\
\hline 1 & 0,5 & 12 & 5 & 25 & 20 & 60 & 170 & 650 & 400 & 250 & 80 & 5 & $1.00 \mathrm{E}+10$ \\
\hline 2 & 0,2 & 1 & 12 & 30 & 34 & 53 & 350 & 5000 & 2500 & 1500 & 200 & 35 & $1.00 \mathrm{E}+03$ \\
\hline 3 & 0,2 & 1 & 5 & 16 & 32 & 53 & 538 & 5254 & 1893 & 377 & 97 & 5 & $1.00 \mathrm{E}+03$ \\
\hline 4 & 0,6 & 4 & 6,2 & 31,5 & 65 & & 270 & 800 & 76 & 31 & 5 & 3000 & \\
\hline 5 & 0,25 & 1,2 & 27 & 19 & 31 & & 410 & 8860 & 2900 & 300 & 13 & 145 & \\
\hline 6 & 0,6 & 8 & 10 & 10 & 18 & 85 & 250 & 640 & 490 & 80 & 180 & $6 \mathrm{E}+00$ & $1.00 \mathrm{E}+10$ \\
\hline 7 & 0,6 & 6 & 10 & 10 & 30 & 40 & 2000 & 2150 & 500 & 400 & 200 & 30 & $1.00 \mathrm{E}+10$ \\
\hline 8 & 0,34 & 6 & 28 & 40 & 50 & & 150 & 3505 & 552 & 80 & 10 & 1500 & \\
\hline 9 & 0,6 & 4,5 & 6 & 37 & 25 & 15 & 250 & 1800 & 100 & 200 & 90 & 16 & $1.00 \mathrm{E}+10$ \\
\hline 10 & 0,33 & 4 & 13 & 30 & 25 & & 160 & 3500 & 790 & 60 & 3 & 1000 & \\
\hline 11 & 0,8 & 2 & 4 & 5 & 25 & 90 & 800 & 950 & 120 & 60 & 12 & 5 & $1.00 \mathrm{E}+10$ \\
\hline 12 & 0,5 & 4 & 9 & 13 & 27 & 44 & 1500 & 5000 & 950 & 500 & 70 & 5,5 & $1.00 \mathrm{E}+10$ \\
\hline 13 & 0,45 & 4 & 9 & 13 & 21 & 55 & 600 & 4000 & 900 & 200 & 60 & 4 & $1.00 \mathrm{E}+10$ \\
\hline 14 & 0,3 & 16 & 32 & 10 & 30 & & 883 & 8000 & 800 & 75 & 15 & 5000 & \\
\hline 15 & 0,6 & 2 & 3 & 19 & 25 & 43 & 250 & 5000 & 300 & 180 & 80 & 2 & $1.00 \mathrm{E}+10$ \\
\hline 16 & 0,2 & 2 & 6 & 13 & 18 & 40 & 1830 & 6150 & 2500 & 200 & 62 & 6 & $1.00 \mathrm{E}+03$ \\
\hline 17 & 0,4 & 5 & 8 & 13 & 20 & 60 & 1000 & 2500 & 950 & 250 & 90 & 4,5 & $1.00 \mathrm{E}+10$ \\
\hline 18 & 0,8 & 7 & 8 & 20 & 30 & 55 & 700 & 4000 & 1500 & 700 & 180 & 48 & $1.00 \mathrm{E}+10$ \\
\hline 19 & 0,8 & 5,5 & 8 & 10 & 20 & 65 & 1700 & 4500 & 1200 & 450 & 90 & 20 & $1.00 \mathrm{E}+10$ \\
\hline 20 & 0,8 & 5 & 8 & 10 & 15 & 57 & 460 & 1800 & 400 & 150 & 90 & 5 & $1.00 \mathrm{E}+10$ \\
\hline 21 & 0,8 & 9 & 8 & 11 & 21 & 54 & 270 & 7800 & 900 & 200 & 80 & 40 & $1.00 \mathrm{E}+10$ \\
\hline 22 & 0,8 & 8 & 7 & 26 & 35 & 62 & 1050 & 4800 & 900 & 600 & 280 & 30 & $1.00 \mathrm{E}+10$ \\
\hline
\end{tabular}

Tabela 2 - Resultado da interpretação quantitativa das SEV's efetuadas no município de Santarém Novo. 


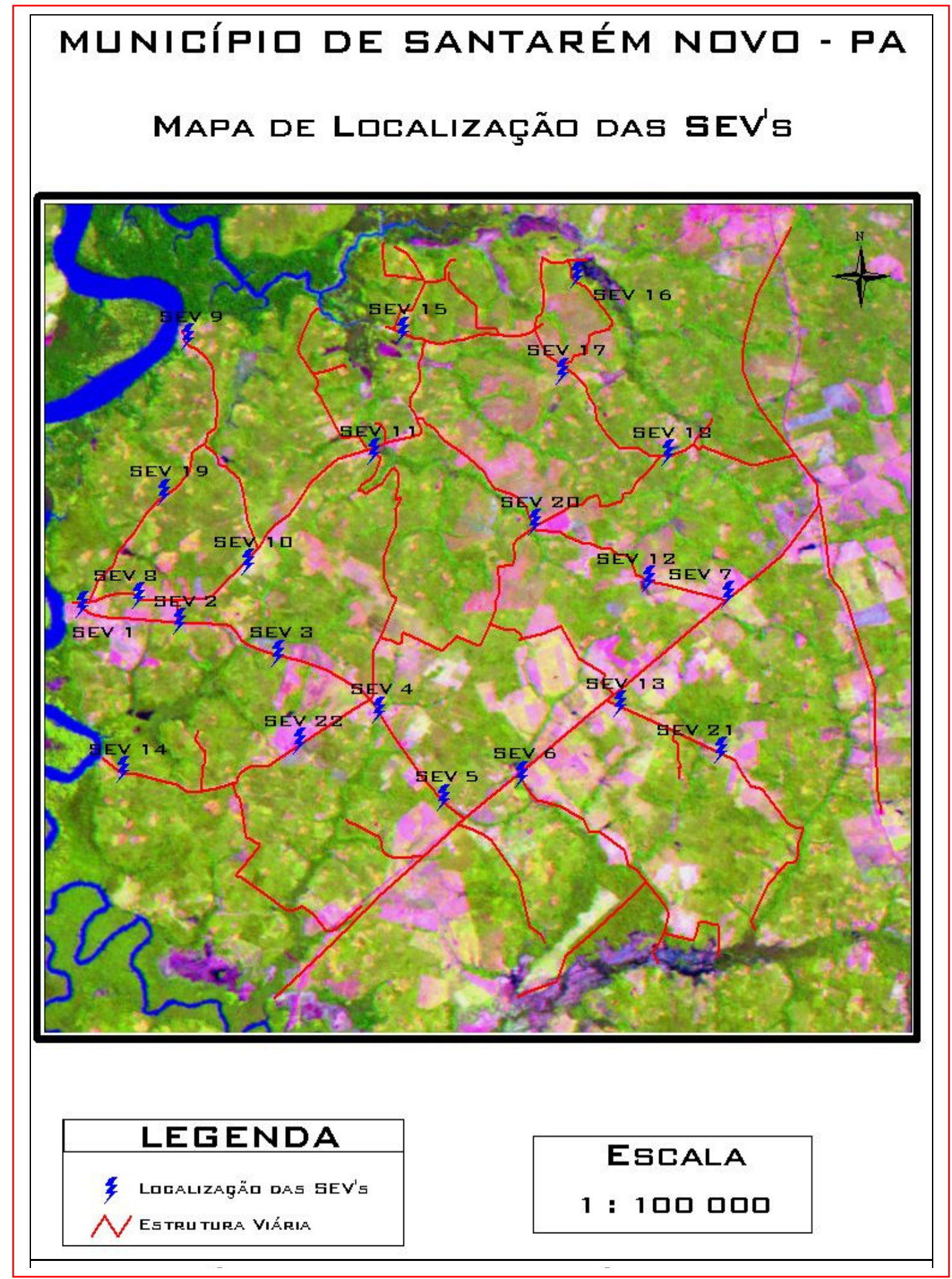

Figura 1 - Mapa de localização das SEV's. 